\title{
A TWO PHASE STUDY TO REVISE THE AUSTRALIAN PRACTICE STANDARDS FOR SPECIALIST CRITICAL CARE NURSES
}

\begin{abstract}
Background: Observational work to develop the ACCCN Competency Standards was undertaken more than 20 years ago. Since then the landscape of critical care nursing as a specialty has changed and it is not known if the Competency Standards reflected contemporary practice.
\end{abstract}

Objectives: To revise the ACCCN Competency Standards for Specialist Critical Care Nurses to ensure they continue to meet the needs of critical care nurses and reflect current practice.

Methods: A two-phased project was undertaken. In Phase I focus groups were held in all states. Thematic analysis was conducted using two techniques. The Standards were revised based on the main themes. Phase II consisted of an eDelphi technique. A national panel of critical care nurses responded to three survey rounds using a 7 point likert-type scale to indicate their level of agreement with the revised standards. A $70 \%$ agreement level for each statement was determined apriori.

Results: Phase I: 12 focus groups (79 participants) were conducted. Phase II: A panel of specialist critical care nurses (research, management, clinical practice and education) responded to round $1(n=64)$, round $2(n=56)$, and round $3(n=40)$. Fifteen practice standards with elements and performance criteria were grouped into four domains (Professional practice, Provision and coordination of care, Critical thinking and analysis, Collaboration and leadership). The revised Practice Standards for Specialist Critical Care Nurses build upon and are additional to the Nursing \& Midwifery Board of Australia National Competency Standards for Registered Nurses. The standards reflect contemporary critical care nurse practices using an expanded 
range of technologies to care for complex critically ill patients across the lifespan in diverse settings.

Conclusion: The national study has resulted in the $3^{\text {rd }}$ edition of the Practice Standards for Specialist Critical Care Nurses. There was input from stakeholders and agreement that the revised standards capture contemporary Australian critical care nursing practice.

\section{Keywords}

Competencies; practice standards; specialist; intensive care; critical care; nursing

\section{Introduction}

Over the last 30 years nursing has seen the development and proliferation of registration level ${ }^{1,2}$ and specialist level standards for practice ${ }^{3-7}$. Standards provide a framework to describe professional practice of a specific level ${ }^{8}$. As early as 1985 the antecedent Confederation of Australian Critical Care Nurses (now the Australian College of Critical Care Nurses [ACCCN]) developed the Standards for Nursing Care of Critically III Patients ${ }^{9}$

Five years later the ACCCN adopted a competency-based approach for critical care nurse standards. This decision was influenced by the 1990 Nurse Competency Assessment Project ${ }^{10}$ that determined minimum competencies for registered nurses, as well as the National Training Board promotion of the development of competency-based standards. The 1996 Competency Standards for Specialist Critical Care Nurses articulated the clinical practice of experienced critical care nurses. They were the result of a multi-centre mixed methods study that included data collection in more than 50 hospitals and observation of over 100 specialist and expert critical care nurses by trained observers (resulting in almost 1000 hours of observed practice), with further validation at a national workshop ${ }^{11}$. A strength of the Competency Standards for Specialist Critical Care Nurses ${ }^{12,13}$ was 
their development from a rigorous research process of observation of specialist critical care nurses. The research methodologies were found to be robust in comparison to other critical care nursing practice standards $s^{3-6,14}$ that had been predominately developed using expert panels ${ }^{15}$.

Between 2001 and 2002 a modified Delphi technique was used to assess the ongoing validity of the Competency Standards for Specialist Critical Care Nurses ${ }^{12}$. The expert panel of 40 experienced critical care nurses reached $70 \%$ agreement on the revised standards in two Delphi rounds. Changes to the first edition were relatively minor and consisted of deleting repetition and editorial changes to increase clarity and application of the standards ${ }^{13}$.

The ACCCN recommended that the Competency Standards for Specialist Critical Care Nurses ${ }^{13}$ be used to inform curricula development and assessment of clinical practice in critical care nurse education ${ }^{16}$. This recommendation has been widely adopted by education providers ${ }^{17,18}$. Gill, Leslie, Grech, \& Latour ${ }^{18}$ reported that 17 of 22 of critical care course providers (77\%) utilised the ACCCN Competency Standards for Specialist Critical Care Nurses ${ }^{13}$ as a guiding framework for assessment of student clinical performance. Despite their wide spread use as an assessment tool, the validity of using the Competency Standards for Specialist Critical Care Nurses ${ }^{13}$ for this purpose has been challenged. Fisher, Marshall \& Kendrick ${ }^{19}$ found they had very weak construct validity, and suggested the validity could be strengthened by modifying from six into four domains. The six original domains were; Enabling, Clinical problem solving, Professional practice, Teamwork and Leadership. The organised clustering of related competencies into these six domains was further questioned when overlap and repetition across domains was identified in the context of clinical performance assessment ${ }^{20}$.

In addition to the lack of support for the existing six domain model, it is unknown if the Competency Standards for Specialist Critical Care Nurses ${ }^{13}$ continue 
to reflect current critical care nurse practice. The original observation of specialist practice was undertaken in 1993, when Australia and the world were very different to the environments we face now. For example access to hospital intranet where policies and procedures are stored, the patients' health care journey is tracked ${ }^{21}$ and external databases used to access evidence based literature was limited ${ }^{22}$, also the digital revolution was in its infancy and advanced technologies used to support life were not part of everyday practice ${ }^{23}$. In addition, the workforce in Australia has changed with a majority of the workforce employed part-time ${ }^{24}$ which may limit access to performance development opportunities. Further, there are national ${ }^{25}$ and employer $^{26}$ requirements for a nurse to be capable of safely performing ${ }^{27}$ to professional or industry standards which ultimately impact upon the development of competencies or standards for practice. The aim of the research was to revise the Competency Standards for Specialist Critical Care Nurses ${ }^{13}$ to ensure they continue to meet the needs of critical care nurses and reflect contemporary clinical practice.

\section{Methods}

An ACCCN working group agreed on the research design for the revision. Considered most appropriate was a mixed methods approach of integrating qualitative and quantitative data to build on findings. The qualitative data were collected using focus groups and the Delphi technique was a quantitative method used to build on, validate or corroborate the results ${ }^{28}$. The Delphi technique had also been previously used in the revision of the $1^{\text {st }}$ edition of the Competency Standards for Specialist Critical Care Nurses, ${ }^{12}$ where the expert panel reached greater than $70 \%$ agreement after the first Delphi round. The revision process was thus undertaken in two phases: Phase I consisted of focus groups with specialist critical care nurses to explore their views about the Competency Standards for Specialist Critical Care Nurses ${ }^{13}$ and identify any changes required to reflect contemporary 
practice. Phase II consisted of a modified Delphi technique to reach expert panel agreement on the revised standards.

Nine other specialty nurse organisations contributed to the original observational work. Eight of these organisations have since developed their own competency standards ${ }^{29-31}$. In recognition of the good will generated through the original collaboration, and acknowledging that several organisations had since used the ACCCN work as a basis for their own competency standards, an invitation was extended to these groups to participate in the revision. None of the groups accepted the invite to contribute. A health consumer representative was also invited to contribute to the revision by providing comments and feedback on the revised draft document.

\section{Ethical considerations}

Ethics approval was obtained for both phases of the study from a university Human Research Ethics Committee. Focus group participants provided written informed consent. The interviews were audio-recorded and field notes were taken. The Delphi panel members were informed that consent was inferred by the submission of the completed surveys.

\section{Phase I Focus Groups}

For the focus groups, purposive sampling was used to select critical care nurses who had experience in using the ACCCN Competency Standards for Specialist Critical Care Nurses ${ }^{13}$ in clinical practice, management or education. Participants were recruited through expressions of interest circulated via the ACCCN networks, publications, and opportunistically at face-to-face meetings and conferences. Focus group facilitators were trained by the researchers and a pilot focus group was conducted with a convenience sample of nurses. Following the first focus group, the research team reviewed the transcript and made minor refinements to the interview 
guide wording to improve clarity. Twelve focus groups were held in six states between June and December 2013 using four semi-structured interview questions.

1. How have the Competency Standards for Specialist Critical Care Nurses ${ }^{13}$ been used? And how could they be used?

2. Should the Competency Standards for Specialist Critical Care Nurses ${ }^{13}$ be broadened or be more specialised?

3. Has the role of specialist critical care nurse changed since the original Competency Standards for Specialist Critical Care Nurses ${ }^{12}$ were developed in 1990s?

4. What has changed since the Competency Standards for Specialist Critical Care Nurses ${ }^{13}$ were last reviewed?

\section{Data Analysis}

\section{Phase I Focus Groups}

A systematic approach was used to conduct, analyse and report this study $^{32,33}$. Two techniques were used to analyse focus group data: a traditional thematic content analysis of transcribed recordings and an alternative approach using the recording themselves and field notes. Each approach incorporated a transparent structure with defined sequence of analytical stages for data analysis, with the benefit of viewing the data from different perspectives ${ }^{34}$. Using traditional thematic content analysis as the methodological framework, a structured multi-step process was followed ${ }^{35,36}$. The audio-recordings were first transcribed verbatim and the field notes used to maintain contextual detail. The transcripts were then read through by two of the research team (FG \& HD) to obtain an overall perspective of the information. Next, the transcript content data were coded using the interview questions as the primary categories. Together FG \& HD crosschecked the codes. Sections of the transcribed text that reflected similar ideas were grouped together 
and given a representative code. The codes were examined using a constant comparison process where each code was compared to the rest of the data to establish the themes. There were several revisions to the organisation of the themes and development of subthemes imputed from the codes ${ }^{37}$. Simultaneously an alternative approach was undertaken by two researchers (MG and TK). This technique, used in analysis of interview data ${ }^{38}$ involved independently listening to the actual recordings from the focus groups along with field notes by each of the two researchers. Themes were identified and developed from analysis of the audiorecordings and field notes ${ }^{38}$. Notes and emerging themes were compared (MG and TK) with consensus agreement achieved.

Finally all members of the research team reviewed the themes identified via both analytical approaches to reach consensus and confirm the themes and subthemes. No new themes or subthemes were identified by using the different approaches.

\section{Findings}

\section{Phase I Focus Groups}

\section{Participants}

Seventy nine critical care nurses participated in the 12 focus groups. Table 1 presents the characteristics of the participants and shows that half worked in cities (51\%) in the adult intensive care setting (51\%). Participants were very experienced critical care nurses (mean 16 years experience), with almost all holding graduate level qualifications with $21.5 \%$ at Master or $\mathrm{PhD}$ level.

\section{INSERT Table 1 here}

The focus group findings are presented using the four interview questions as the main categories. The summary of themes and subthemes are shown in Figures 1-4. 
Codes have been included after each intext quote to identify the origin of the focus group by State (QLD, NSW, VIC, TAS, SA or WA and focus group 1, 2 or 3).

How have the standards being used and how should they be used?

Participants identified that the Competency Standards for Specialist Critical Care Nurses ${ }^{13}$ were used for three main purposes: (1) for evaluating the performance of nurses in the workplace, (2) for professional development and (3) to guide postgraduate education curricula. The Standards could be used more widely in clinical practice, although the impact of the Standards being unavailable in recent years had resulted in a lack of visibility in some workplaces.

It was evident that the first way the Competency Standards for Specialist Critical Care Nurses ${ }^{13}$ were being used was for the assessment of clinical performance. A participant described how they had found them useful when asked by her manager to complete an annual performance of what she had achieved: “...they handed us this sheet and these are all of the things that we hope you've met and tell us how you have met those things". And you were competent or expert or whatever. I went through and answered each one of them with specific incidences from that past year, things l'd done or patients I had or incidents that happened in the unit ..." (NSW 1). Another example of how the Competency Standards for Specialist Critical Care Nurses ${ }^{13}$ were being used for assessing professional practice included situations of poor performance and in one response was singled out as the only time they were utilised "...only if it's for staff performance management issue, it will certainly get utilised and that usually comes through our education department to oversee that" (VIC 1). Individuals whose performance was below expectations were measured against the Competency Standards for Specialist Critical Care Nurses ${ }^{13}$ : "I think unfortunately in the situation where l've seen them pulled in my unit it's been when there's been a performance management issue and you're grappling at things, 
because it is quite hard to go through that process. So you pull them out and you go ok you are not demonstrating this, this and this. This is what we would expect of you at this level..." (NSW 2).

The second way the Competency Standards for Specialist Critical Care Nurses ${ }^{13}$ were being used was for professional development which was interpreted by participants as either the competencies used for benchmarking against individual learning needs, or linked to regulation of the profession ${ }^{39}$. In this example a nurse had used the standards as a reference guide when required to submit a professional portfolio for the purpose of maintaining registration "...I was one of the people who got audited...I actually grabbed this as the competency standard that I should compare myself with for the portfolio" (VIC 2).

The third way the Competency Standards for Specialist Critical Care Nurses ${ }^{13}$ had been used was as a guide for the development of academic content or clinical performance assessment for hospital or university conducted postgraduate education: "Yeah, each of the universities has a different way of putting their competencies together. So they might use them, or I see them being used as a skeleton but they don't come out looking exactly like that, each of them are changed according to what the university sees as their focus" (SA 1). Another response showed how the content of postgraduate courses and student assessment has been influenced by competency standards: "The content of that isn't explicit in mind, but it does incorporate a lot of the components of these competencies so a lot of the bases are covered" (WA 1).

Participants agreed that the impact of the Competency Standards for Specialist Critical Care Nurses ${ }^{13}$ being out of print in recent years and under revision for the last two years was a decreased awareness in the workplace: "you can't get your hands on a copy" (TAS 1). Participants described how they thought the standards should be used for performance evaluation: "they could be incorporated in 
job descriptions" (WA 2) and "if I was a manager I would certainly be using these for all of my performance review for all of my staff in an ICU' (NSW 1). What was also needed was different formatting to facilitate the useability of the Standards: "in this era of ongoing CPD which we all need to collect, is turning them into some sort of template tool for reflection and for planning professional development "(VIC 2)

Insert Figure 1 here.

Should the scope of the standards remain broad and include all critical care areas or focus on particular areas?

In exploring whether the Competency Standards for Specialist Critical Care Nurses ${ }^{13}$ continue to adequately reflect critical care nursing practices, it was clear that there are now a greater variety of roles than were previously available when the standards were originally developed: “...and there’s many more avenues of specialist critical care nurses as well, like little branches of specialties. Like liaison nurses, ... , research, data collectors, nurse consultants" (VIC 1).

When asked whether the scope of practice standards should change, participants' views were that the existing standards were appropriate in being broad enough to be relevant in any of the many critical care settings: "You wouldn't want to be too specific. You wouldn't get down to the VAD [Ventricular Assist Device] or ECMO [Extracorporeal Membrane Oxygenation] it's not going to be realistic" (WA 2) and "I completely support that. You are spot on. You can't make it too specific" (WA 2).

Insert Figure 2 here. 
What does a specialist critical care nurse look like now? Is this person different from what the Competency Standards for Specialist Critical Care Nurses ${ }^{13}$ describe or is it only the context that has changed?

In response to this question participants reported that core business was unchanged but there have been changes to the practice environment. "I think the same illnesses are still killing people now, sepsis is still the biggest killer in ICU" (TAS 1). The impact of technology was reported to have changed the way critical care nurses work at the bedside:“...it's such a big part and a rapidly growing part of what critical care nurses deal with every day, but their skills and abilities with technology need to be far greater now..." (WA 2).

There was also agreement amongst participants that the level of content detail for the Competency Standards for Specialist Critical Care Nurses ${ }^{13}$ was still relevant:“...when I read back through it I was looking for anything that was no longer relevant or could be taken out and I just felt that it was all really still relevant and yeah needed to be there" (VIC 2), and whether scenarios used in the original document continued to reflect contemporary practice: "Some of the examples could probably be tweaked...but I think the whole document has actually aged very well" (WA 1).

Insert Figure 3 here

If we now look at the 2002 Competency Standards could you tell us what if anything, has changed since their publication? Are there any new competencies, any deletions required, any changes needed?

Participants discussed the differences in critical care nurses' relationship with patients and families: "I think the difference is in the consumer, dare we call them that, so the relative, I think over the 20 years, there are now relatives coming in 
wanting and seeking more, and wanting more engagement. (WA 2). Despite this major practice difference, there was agreement that the competency standards already adequately reflected the socio-emotional care of families and no changes were required.

Three main changes to the standards required were identified in order to (1) reflect the widespread use of communication technologies in healthcare, (2) align with the National Competency Standards for Registered Nurses ${ }^{39}$ and articulate specialist progression in the context of critical care nursing (3) be easily accessible and widely available.

Participants described how patients' relatives now readily accessed information: "I think that's where the technology comes in now, if they don't understand a piece of equipment or what you've said they will google it and they will come back to you and say well you said this about that..."(WA 2). Using mobile phones generated discussion about the appropriateness of using this technology at the bedside: "And the nurse manager smacks you on the wrist and says put that away you can't have your phone out...l need to set an example for the junior nurses...l'm showing them technology that's accessible and here's a resource for you to use at the bedspace when the hospital internet is so slow that you can't use it" (NSW 1). Further the issue of patient confidentiality was raised as a concern: "I suppose the camera's an issue isn't it" (NSW 2) and "So using your phone... professionally, appropriately, not taking them into the room and showing them photos of your patients" (NSW 3).

Participants were aware of the proposed changes to the National Competency Standards for the Registered Nurse ${ }^{39}$ including the change of terminology from competency standards to standards for practice ${ }^{40}$, the number of practice domains had been reduced to four, and identified that the critical care standards should be aligned: "...l do like...idea of narrowing it down to the 
competencies under the NMBA (Nursing and Midwifery Board of Australia)" (VIC 2) and "it would be four domains" (VIC 1).

Better accessibility to the standards for critical care nurses was highlighted as important. This included a marketing and distribution strategy so nurses were more likely to use them: "I think it would be useful if they were a free download...you only know they are available to buy if you're a member of ACCCN. But if you want people to more widely use them l'd make them a free down load" (NSW 3).

Insert Figure 4 here.

Phase I identified that the Competency Standards for Specialist Critical Care Nurses $^{13}$ were being used in a number of ways for assessment of clinical performance. The impact of the Competency Standards for Specialist Critical Care Nurses ${ }^{13}$ being out of print and unavailable over recent years was a decreased awareness about their existence. Although critical care nurse practice areas had expanded, it was agreed that standards should remain broad enough to be relevant to all. Practice changes that had occurred over the last 20 years and considered relevant to apply to this revision were identified as; an increased consumer focus to include psycho-social care of the patient and family, the increased use of technology at the bedside and the preference for the Competency Standards for Specialist Critical Care Nurses ${ }^{13}$ to be renamed as Practice Standards for Specialist Critical Care Nurses and arranged into four practice domains. It was also emphasised that the revised standards should be easily accessible.

\section{Phase II eDelphi method}

The themes identified from the Phase I focus groups guided the changes that were made to the statements contained in the Competency Standards for Specialist 
Critical Care Nurses ${ }^{13}$. For Phase II the eDelphi method consisted of the iterative process of administering three rounds of surveys to a national panel of critical care nurse experts using web-survey software. In the first survey round, panel members were asked to rate their level of agreement with the draft statements rather than using the classic Delphi technique of responding to open questions ${ }^{28}$. The panel

A purposive sampling strategy was used to recruit panel members through expressions of interest circulated via the ACCCN networks, publications, and other activities such as the College's Facebook page and critical care discussion lists. In addition, an invitation was issued to members of other specialty nursing organisations who were involved in the original competency standards project. The panel selection criteria were: a) experience using the Competency Standards for Specialist Critical Care Nurses ${ }^{13}$ in clinical practice, management or education, b) graduate level critical care qualification ${ }^{41}$.

The panel members represented nurses from metropolitan, regional and rural critical care settings as well as all states and territories to obtain the perspectives of all stakeholders. The target size for the panel was 100 to allow for some attrition over the Delphi rounds ${ }^{28}$.

Survey development

The Competency Standards for Specialist Critical Care Nurses ${ }^{13}$ were revised to reflect the focus group findings, and also Fisher et al's. recommendations to reduce the number of domains ${ }^{19}$. This process involved a number of steps. The standards were first re-organised into four domains and this highlighted where there was overlap in the standards and elements. The term elements is used to describe a second level of statements that articulate aspects of performance that, when reviewed collectively would be regarded as evidence of effective performance within a specific competency ${ }^{12}$. The statements were reduced to 15 standards (representing 
competencies) and 42 elements. Wording changes were made to also incorporate the focus group recommendations for less jargon and to use familiar terminology.

For the round 1 survey no performance criteria (concrete examples of behaviour that is evidence of effective ability within an element) were included. This was to provide the opportunity for the panel to suggest new performance criteria. The title for the draft statements was changed to Practice Standards for Specialist Critical Care Nurses at this point so as to obtain panel feedback. Feedback from the health consumer representative was also incorporated at this stage. This included recommendations around terminology used to encompass 'family', nurse-patientfamily communication styles and maintaining a therapeutic environment (eg minimise noise and enhance normalised sleep pattern).

For the round 1 survey, a seven point rating scale was used with panel response choices ranging from strongly disagree to strongly agree. The panel was also invited to make comments and suggestions to add to or clarify the statements and suggest new and contemporary performance criteria. For the round 2 survey, the panel was again requested to indicate the level of agreement for each statement and also invited to make comments and suggestions. For the round 3 survey, the panel was requested to indicate level of agreement only.

The survey and data collection processes were first pilot tested, as recommended by Presser et al. ${ }^{42}$, by five academics and critical care nurses who provided feedback and comments about the statements, process, survey instructions and ease of completing the survey. No difficulties were encountered with the process and feedback resulted in minor wording changes and editing for clarity only.

\section{Distribution of eDelphi survey rounds}

Web-survey software SurveyMonkey@ was used to administer the eDelphi process. For each round of surveys, two follow up reminder emails per round were 
sent to non-responders. The round 2 surveys were sent only to participants who responded to round I and for round 3, surveys were sent only to participants who responded to round 2 .

\section{Data analysis}

\section{Phase II eDelphi method}

A response rate of greater than $70 \%$ per round was considered to be acceptable to avoid the occurrence of response bias if attrition was substantial ${ }^{28}$. The round 1 survey panel feedback was reviewed and comments and suggestions relevant to the topic were included in round 2 and 3 surveys. The web-survey software was used to generate stacked bar charts illustrating the distribution of responses by level of agreement. Data were imported into SPSS and descriptive statistics including frequency distributions were computed. For the level of agreement rating scale, responses were reported as median and interquartile ranges. A priori level of panel agreement was set at $70 \%$. This was assessed as a response median score of 5 or more. The responses to elements were also ranked by highest mean and smallest standard deviation.

\section{Findings}

\section{Phase II eDelphi method}

The eDelphi survey data were collected between August and December 2014 . Of the 74 critical care nurses who agreed to participate, $64(86 \%)$ responded to the first round. The response rate in round 2 was 56 (76\%) with 40 responses (71\%) in round 3. 


\section{Panel demographic characteristics}

Table 2 presents the characteristics of the panel for round 3 and shows that over $50 \%$ described their practice area as adult intensive care.

INSERT Table 2 here

\section{Round 1}

The panel comments and feedback resulted in editing of elements and deletion of seven elements to avoid duplication. No new concepts were identified and there were positive comments about the reduction in the number of domains from six to four and the reduction in the number of standards from 20 to 15 (Table 3). The round 2 survey consisted of the 15 standards and 36 elements, each with a number of performance indicators.

INSERT Table 3 here

\section{Round 2}

Panel comments in round 2 enabled further refinements for wording clarity and additional performance indicators. There were no further additions or deletions to the 36 elements in the round 3 survey.

\section{Level of agreement scale}

Of the total of 36 elements, the level of agreement for 10 elements was rated as median 7(6-7) and 26 elements were rated as median 5(5-5). All elements achieved $70 \%$ agreement. The ranking of mean responses for each element is presented in Table 4.

INSERT Table 4 HERE 


\section{Discussion}

Consumers of healthcare, their families and the broader regulatory authorities such as the Nursing and Midwifery Board of Australia ${ }^{43}$ and the Australian Commission for Safety and Quality in Healthcare ${ }^{25}$ expect excellence in the provision and monitoring of nursing care. The development of the 2015 edition of Practice Standards for Specialist Critical Care Nurses ${ }^{44}$ was the result of a systematic process to ensure that the standards reflect contemporary specialist critical care nurse practice. The methodology used for this revision was chosen first using focus groups to obtain the views of critical care nurses who had experience using the 2002 edition of the Standards. This was to listen and gather information to understand users' perspectives ${ }^{35}$. After the suggested changes were incorporated, the modified Delphi was used to gain expert panel consensus by rating the importance of the statements developed from the focus groups ${ }^{28}$. The expert panel reached agreement on the predetermined consensus level of $70 \%$. Similar consensus studies have been widely utilised in nursing and health research ${ }^{27,45-49}$

The revised Standards have undergone a name change from 'Competency Standards' to 'Practice Standards', the domains were reduced from six to four and the number of standards reduced from 20 to 15. The Practice Standards for Specialist Critical Care Nurses ${ }^{44}$ are thus condensed, reflecting the feedback from users to be more user friendly and reduce previous overlap. This shift to a more concise articulation of the expectations of nurse practice is also seen in the updated Nursing and Midwifery Board of Australia's (NMBA) registered nurse standards for practice $^{50}$ where the previous 10 standards were reduced to seven. Although the research to revise the Competency Standards for Specialist Critical Care Nurses ${ }^{13}$ was completed prior to the release of the NMBA registered nurse standards for practice, by comparing the two sets of practice standards it is evident how the registered nurse can progress from beginning practice to specialty level practice in 
the context of critical care. There are organisational differences between the two sets of standards in that, unlike the Practice Standards for Specialist Critical Care Nurses $^{44}$, the seven NMBA registered nurse standards for practice ${ }^{50}$ are not clustered into domains.

This research confirmed that the Competency Standards for Specialist Critical Care Nurses ${ }^{13}$ are still relevant to today's critical care nurse practice. The level of detail remains appropriate and enables the Standards to be applied in a variety of critical care settings. This study also confirmed that the Standards were being used mainly for the purpose of assessment of clinical performance. In the context of postgraduate education, it had already been identified that the Standards were being adapted to reflect the practice expectations for graduates of critical care education programs, ${ }^{17,18}$ and there has been recent work to clearly articulate these practice expectations ${ }^{51,52}$. It will be interesting to follow how the graduate practice standards ${ }^{51,}$ 52 are used and how these might impact on the use of the Practice Standards for Specialist Critical Care Nurses ${ }^{44}$ for the assessment of student clinical performance in critical care education programs.

The minor changes that were recommended reflect healthcare's increased emphasis on quality and safety informed practice, expanded roles for critical care nurses, the use of hand held technology such as mobile phones and tablets at the bedside for patient and staff education ${ }^{53}$ and the increased expectation to practice patient and family centred care. Critical care has now extended well beyond the walls of the traditional intensive care setting to include acute care delivery of technologies and treatments ${ }^{54}$. Appropriate performance indicators were included to reflect such diverse settings.

The increased focus on consumers and patient and families ${ }^{55}$ was acknowledged by focus group participants. No wording changes were required as the existing standards already well described the critical care nurse relationship with 
patients and families. Despite this acknowledgement of the importance of patient and family centred care, it is interesting that the Delphi panel level of agreement with the elements of Standard 5 "Promotes patient and family centred care" was only $70 \%$, perhaps indicating that critical care nurses have yet to fully embrace this practice.

Since the observational work undertaken to produce the 1996 Standards, nursing practice has changed in terms of the use of hand held tablet based technology to readily access information ${ }^{56,57}$ and to provide patient or staff education ${ }^{53}$. This was not reflected in the previous edition of the competency standards, so wording changes were made. While it was acknowledged that this is an important influence on today's practice and environment, caution is required to ensure the appropriate use and governance of such technologies ${ }^{58,59}$ Finally the study participants emphasised that ready availability and easy accessibility are essential for the new Standards to be widely disseminated and used. A comprehensive marketing strategy will enhance the visibility of the Standards and promote their use by managers, clinicians and educators.

There were a number of limitations to the study. The study methods were selected to address the research aim of revising the Competency Standards for Specialist Critical Care Nurses ${ }^{13}$ to ensure they continued to reflect contemporary critical care nurse practice, based on the assumption that the Competency Standards for Specialist Critical Care Nurses ${ }^{13}$ still had relevance and required updating only. This assumption was confirmed initially by the focus group findings and strengthened by achieving consensus using the Delphi technique. If the findings had been that critical care nurse practice had changed greatly, a further observational study would have been appropriate.

There were 40 Delphi panel members who responded to the round 3 survey. Although there is no agreement on an ideal panel size ${ }^{60}$, this was smaller than anticipated. An ideal panel size is a balance between large numbers being difficult to 
manage and having high attrition rates versus small numbers in a panel and potentially introducing bias and lack of generalisability ${ }^{60}$. The attrition rate was low (more than $70 \%$ panel response rate retained for each survey round).

Finally, following the 2016 release of the NMBA registered nurse standards for practice ${ }^{50}$, it is now known that these standards are not organised into domains. If this information was available at the time of the research it may have influenced the organisation of the Practice Standards for Specialist Critical Care Nurses ${ }^{44}$. Without this prior knowledge, the structure of four domains and 15 standards was found to be acceptable to the national panel of critical care nurses. A future revision project will be the opportunity to examine this further.

\section{Conclusion}

The two-phase study has resulted in the $3^{\text {rd }}$ edition of ACCCN Practice Standards for Specialist Critical Care Nurses ${ }^{44}$. Major strengths of the study include a national focus, input from stakeholders and ongoing consensus that the standards capture contemporary Australian critical care nursing practice in addition to now more closely aligning with and building upon the Australian Competency Standards for the Registered Nurse ${ }^{39}$. Critical care nurses can use the $3^{\text {rd }}$ edition of the Practice Standards confidently in the way that they were originally intended: as the "gold standard' description of Australian specialist level critical care nurse practice. Future work can now focus on two major areas. These include the development of resources to facilitate critical care nurses to align activities, e.g. Continuing Professional Development, against the Standards, ideally in electronic format. Further exploration for the Standards' construct validity is recommended if they are to be used confidently as a tool to assess clinical practice. 


\section{References}

1. American Nurses Association. Nursing: scope and standards of practice [internet]. Washington DC: American Nurses Association; 2004. Available from: http://www.nursesbooks.org/.

2. Homer C, Passant L, Kildea S, Pincombe J, Thorogood C, Leap N, et al. The development of national competency standards for the midwife in Australia. Midwifery. 2007; 23(4):350-360.

3. American Association of Critical Care Nurses. AACN Scope and standards for acute and critical care nursing practice [Internet]. Aliso Viejo, CA: American Association of Critical Care Nurses; 2008. Available from: http://www.aacn.org/.

4. Canadian Association of Critical Care Nurses. Standards for critical care nursing practice [internet]. London, Ontario: Canadian Association of Critical Care Nurses; 2009. Available from: http://www.caccn.ca/.

5. Critical Care Networks-National Nurse Leads. National Competency Framework for Adult Critical Care Nurses [Internet]. 2013. Available from: http://www.cc3n.org.uk/competency-framework/4577977310

6. European federation of Critical Care Nursing associations - EfCCNa. EfCCNa Competencies for European Critical Care Nurses, 2013. Available from: http://www.efccna.org/images/stories/publication/competencies_cc.pdf

7. Nursing Council of New Zealand. Competencies for registered nurses [internet]. Wellington, New Zealand: Nursing Council of New Zealand; 2007. Available from: http://www.nursingcouncil.org.nz/.

8. Chiarella M, Thoms D, Lau C, Mclnnes. An overview of the competency movement in nursing and midwifery. Collegian. 2008; 15(2):45-53.

9. Australian Association of Critical Care Nurses. Standards for Nursing Care of Critically III Patients. Sydney: Australian Association of Critical Care Nurses; 1985.

10. Australian Nursing Council Inc. ANCI national competency standards $f$ or the registered nurse, 1990

11. Dunn SV, Lawson D, Robertson S, Underwood M, Clark R, Valentine $\mathrm{T}$, et al. The development of competency standards for specialist critical care nurses. Journal of Advanced Nursing. 2000; 31(2):339346.

12. Confederation of Australian Critical Care Nurses Inc. Competency Standards for Specialist Critical Care nurses, 1996. Subiaco, Western Australia: Ink Press International;

13. Australian College of Critical Care Nurses. Competency Standards for Specialist Critical Care Nurses. 2nd ed. Perth, Western Australia: Cambridge Media; 2002.

14. Critical Care Nurses' Section. Philosophy and standards for nursing practice in critical care [internet]. Wellington, New Zealand: New Zealand Nurses' Organisation; 2002 Available from: http://www.nzno.org.nz/. 
15. Gill F, Leslie G, Grech C, Latour J. A review of critical care nursing staffing, education and practice standards. Aust Crit Care. 2012; 25(4):224-237.

16. Australian College of Critical Care Nurses. ACCCN position statement on the provision of critical care nurse education [Internet]. 2006 Available from:

http://www.accen.com.au/images/stories/downloads/provision CC nur sing edu.pdf.

17. Aitken L, Currey J, Marshall A, Elliott D. The diversity of critical care nursing education in Australian universities. Aust Crit Care. 2006; 19(2):46-52.

18. Gill F, Leslie G, Grech C, Latour J. An analysis of Australian graduate critical care nurse education Collegian. 2015; 2(1):71-81.

19. Fisher MJ, Marshall A, Kendrick T. Competency standards for critical care nurses: do they measure up? Aust J Adv Nurs. 2005; 22(4):32-39.

20. Gill F, Leslie GD, Southerland K. Evaluation of a clinical performance assessment tool (CPAT) within a critical care context. Aust Crit Care. 2006; 19(3):105-113.

21. Dinh $\mathrm{M}$, Chu M. Evolution of health information management and information technology in emergency medicine. Emergency Medicine Australasia. 2006; 18:289-294

22. The History of Social Media. http://mashable.com/2011/01/24/thehistory-of-social-media-infographic/;

23. Tunlinda A, Granströmb J, Engström A. Nursing care in a hightechnological environment: Experiences of critical care nurses. Intensive Crit Care Nurs. 2015; 31(116-123).

24. ReserveBankofAustraliaBulletin. The Changing Composition of the Australian Workforce. http://www.rba.gov.au/publications/bulletin/2002/oct/pdf/bu-1002-3.pdf;

25. Australian Commission on Safety and Quality in Health Care (ACSQHC). Vital signs 2015: The State of Safety and Quality in Australian Health Care. Sydney: ACSQHC; 2015.

26. Oliver B, Whelan B, Hunt L, Hammer S. Accounting graduates and the capabilities that count: Perceptions of graduates, employers and Accounting academics in four Australian Universities. Journal of Teaching and Learning for Graduate Employability. 2011; 2(1):2-27.

27. Bromley P. Using eDelphi to identify capability requisites for postgraduate certificate in Neonatal Intensive Care Nursing. Journal of Neonatal Nursing. 2015; 21(6):224-236.

28. Keeney S, McKenna H, Hasson F. The Delphi Technique in Nursing and Health Research. Chichester: Wiley; 2010.

29. Australian College of Neonatal Nurses Inc. Competency Standards for Neonatal Nurses. Canberra, ACT: Australian College of Neonatal Nurses Inc; 2007.

30. College of Emergency Nursing Australasia. Practice Standards for the Emergency Nursing Specialist. 3rd ed: College of Emergency Nursing Australasia Ltd.; 2013.

31. Bonner A, Stewart G. Development of competency based standards: An application of the Delphi research technique. Nurse Researcher. $2001 ; 9(1): 63$. 
32. Schou L, Høstrup H, Lyngsø EE, Larsen S, Poulsen I. Validation of a new assessment tool for qualitative research articles. J Adv Nurs. 2012; 68(9):2086-2094.

33. Tong A, Sainsbury P, Craig J. Consolidated criteria for reporting qualitative research (COREQ): a 32-item checklist for interviews and focus groups. Int J Qual Health Care. 2007; 19(6):349-357.

34. Vaismoradi M, Turunen $\mathrm{H}$, Bondas $\mathrm{T}$. Content analysis and thematic analysis: Implications for conducting a qualitative descriptive study.

Nursing \& Health Sciences. 2013; 15(3):398-405.

35. Krueger R, Casey M. Focus Groups: a practical guide for applied research. 4th edition ed. Thousand Oaks, California: Sage Publication; 2009.

36. Liamputtong $P$, editor. Research methods in health: foundation for evidence based practice. South Melbourne, Victoria: Oxford University Press; 2010.

37. Braun V, Clarke V. Using thematic analysis in psychology. Qualitative Research in Psychology. 2006; 3(2):77-101.

38. Halcomb EJ, Davidson PM. Is verbatim transcription of interview data always necessary? Appl Nurs Res. 2006; 19(1):38-42.

39. Nursing and Midwifery Board of Australia. National competency standards for the registered nurse [Internet]. Dickson, ACT: Australian Nursing \& Midwifery Council; 2010

40. Nursing and Midwifery Board of Australia. Nurse Practitioner Standards for Practice [Internet]. Nursing and Midwifery Board of Australia,; 2014 Available from: http://www.nursingmidwiferyboard.gov.au/CodesGuidelines-Statements/Professional-standards/nurse-practitionerstandards-of-practice.aspx.

41. Australian Qualifications Framework Council. Australian Qualifications Framework. 2nd ed. South Australia: Australian Qualifications Framework Council; 2013.

42. Presser S, Couper MP, Lessler JT, Martin E, Martin J, Rothgeb JM, et al. Methods for Testing and Evaluating Survey Questions. Public Opin Q. 2004; 68(1):109-130.

43. Nursing and Midwifery Board of Australia. [internet]. n.d. Available from: http://www.nursingmidwiferyboard.gov.au/.

44. Australian College of Critical Care Nurses. Practice Standards for Specialist Critical Care Nurses. 3rd ed: ACCCN; 2015.

45. Boulkedid R, Abdoul H, Loustau M, Sibony O, Alberti C. Using and Reporting the Delphi Method for Selecting Healthcare Quality Indicators: A Systematic Review. PLoS ONE. 2011; 6(6):e20476.

46. Chang A, Gardner G, Duffield C, Ramis M. A Delphi study to validate an Advanced Practice Nursing tool. J Adv Nurs. 2010; 66(10):23202330.

47. Crookes $P$, Brown R. The development of a pre-registration nursing comptencies assessment tool for use across Australian universities. Strawberry Hills, NSW, Australia: Australian Learning \& Teaching Council; 2010.

48. Gill F, Leslie G, Grech C, Latour J. Using a web-based survey tool to undertake a Delphi study: Application for nurse education research. Nurse Educ Today. 2013; 33:1322-1328. 
49. Ramelet AS, Gill F. A Delphi study on National PICU nursing research priorities in Australia and New Zealand. Aust Crit Care. 2012; 25(1):4157.

50. Nursing and Midwifery Board of Australia. Registered nurse standards for practice, 1 June 2016.

51. Gill F, Leslie G, Grech C, Boldy D, Latour J. Developing and testing the Standard of Practice and Evaluation of Critical-care-nursing Tool (SPECT) for critical care nursing practice. J Contin Educ Nurs. 2014; 45(7):312-320.

52. Gill F, Leslie G, Grech C, Boldy D, Latour J. Development of Australian clinical practice outcome standards for graduates of critical care nurse education J Clin Nurs. 2015; 24(3-4):486-499.

53. Sawyer T. Implementing Electronic Tablet-Based Education of Acute Care Patients. Crit Care Nurse. 2016; 36(1):60-70 11p.

54. Williams T, Leslie G. Beyond the walls: A review of ICU clinics and their impact on patient outcomes after leaving hospital. Aust Crit Care. 2008; 21(1):6-17.

55. Australian Commission on Safety and Quality in Health Care. Patient centred care. Improving quality and safety through partnerships with patients and consumers. Sydney: Australian Commission on Safety and Quality in Health Care,; 2011.

56. Tuckett A, Turner C. Do you use social media? A study into new nursing and midwifery graduates' uptake of social media. Int J Nurs Pract. 2015:22(2) 197-204.

57. Raman J. Mobile technology in nursing education: Where do we go from here? A review of the literature. Nurse Educ Today. 2015; 35(5):663-672.

58. Currey J, Leslie G. Social networking and professional debriefingPersonal risk management. Aust Crit Care. 2010; 23:103-104.

59. Barlow C, Morrison S, Stephens H, Jenkins E, Bailey M, Pilcher D. Unprofessional behaviour on social media by medical students. Med $\mathrm{J}$ Aust. 2015; 203(11):439.

60. Delbecq A, Gustafson D, Van de Ven A. Group techniques for program planning : a guide to nominal group and delphi processes. Middleton, Wis: Green Briar Press; 1986. 